02

\title{
Спектрально-люминесцентные свойства заряженных форм некоторых замещенных бензальдегидов
}

\author{
() О.К. Базыль ${ }^{1}$, В.Я. Артюхов ${ }^{1}$, Г.В. Майер ${ }^{1}$, П.П. Першукевич ${ }^{2}$, \\ М.В. Бельков ${ }^{2}$, О.И. Шадыро ${ }^{3}$, С.Н. Самович ${ }^{3}$ \\ ${ }^{1}$ Национальный исследовательский Томский государственный университет, \\ 634050 Томск, Россия \\ ${ }^{2}$ Институт фризики НАН Беларуси, \\ 220072 Минск, Беларусь \\ ${ }^{3}$ Белорусский государственный университет, \\ 220030 Минск, Беларусь \\ e-mail: okbazyl@rambler.ru
}

Поступила в редакцию 30.01.2019 г.

В окончательной редакции 25.12.2019 г.

Принята к публикации 27.12.2019 г.

\begin{abstract}
Методами квантовой химии исследованы спектрально-люминесцентные свойства заряженных (анионной и катионной) форм трех замещенных бензальдегидов, проявляющих биологическую активность: $o$-анисового (2-метоксибензальдегид) и сиреневого (3,5-диметокси-4-гидроксибензальдегид) бензальдегидов и ванилина (3-метокси-4-гидроксибензальдегид). Расчеты показали, что в случае заряженных форм исследуемых молекул состояние $S_{1}$ в отличие от нейтральных форм является состоянием $\pi \pi^{*}$-типа и по своей локализации аналогично $S_{2}\left(\pi \pi^{*}\right)$-состоянию нейтральных молекул (анисового альдегида и ванилина) или $S_{3}(\pi \pi *)$ состоянию сиреневого бензальдегида. По результатам расчета показано, что в области спектра $240-420 \mathrm{~nm}$ нет новых электронных переходов, формирующих полосы поглощения в спектре, отличающиеся по природе и локализации от электронных переходов нейтральных молекул. Рассчитанные характеристики флуоресценции заряженных форм исследованных молекул показали, что в отличие от нейтральных форм эффективность радиационного распада заряженных форм много выше, что связано с изменением орбитальной природы состояния $S_{1}$ при переходе от нейтральной к заряженной форме. Согласно анализу расчетных и экспериментальных данных флуоресценции исследуемых замещенных бензальдегидов в спиртовых растворах, флуоресценция на $410 \mathrm{~nm}$ принадлежит катионным формам. В ванилине и сиреневом альдегиде также имеется возможность слабой флуоресценции анионных форм этих соединений.
\end{abstract}

Ключевые слова: замещенные бензальдегиды, спектрально-люминесцентные свойства, методы квантовой химии.

DOI: $10.21883 /$ OS.2020.04.49198.34-19

\section{Введение}

Проблема создания на основе бензальдегида и его гидроксизамещенных (проявляющих биологическую активность) эффективных лекарственных препаратов требует знания их физико-химических свойств и их изменений в зависимости от различных факторов, в частности от свойств среды. Важной структурной особенностью данного класса соединений является их способность образовывать в зависимости от свойств окружающей среды (растворителя, матрицы, добавки и т.п.) заряженные протолитические формы (анионы и катионы) с внутри- и межмолекулярными водородными связями. Известно, что после возбуждения молекулы ее свойства претерпевают изменения из-за изменений в распределении плотности заряда в электронно-возбужденном состоянии по сравнению с основным электронным состоянием. Это обстоятельство сказывается на изменении физико-химических свойств соединений [1]. Одним из способов изучения физико-химических свойств и их изменений являются спектры поглощения и флуоресценции [2]. Поэтому изучение спектрально-люминесцентных свойств бензальдегидов и их заряженных форм актуально.

На первом этапе исследований нами были получены спектры поглощения изучаемых бензальдегидов в гексане и этаноле. Флуоресценцию этих соединений удалось наблюдать только в этаноле [3]. При экспериментальном исследовании молекул бензальдегидов специальных условий для получения заряженных форм не создавалось, поэтому достоверное отнесение полученных спектров поглощения и флуоресценции к конкретной протолитической форме затруднительно. Оно требует детального рассмотрения спектральнолюминесцентных свойств этих соединений в средах с различными донорно-акцепторными свойствами и результатов квантово-химических расчетов. В работе [3] приведены результаты квантово-химического расчета нейтральных форм (НФ) этих соединений. Анализ полученных экспериментальных и теоретических результатов 
позволил заключить, что НФ изученных замещенных бензальдегидов не отвечают за наблюдаемую флуоресценцию растворов в этаноле.

В настоящей работе выполнены квантово-химические расчеты спектрально-люминесцентных свойств заряженных форм (анионных - АФ и катионных - КФ) трех замещенных бензальдегидов: 2-метоксибензальдегид (oанисовый альдегид), 3-метокси-4-гидроксибензальдегид (ванилин), 3,5-диметокси-4-гидроксибензальдегид (сиреневый альдегид) (рис. 1).

Отметим, что главная цель наших исследований спектрально-люминесцентных свойств биомолекул состоит в установлении взаимосвязи „электронная структура-спектроскопические свойства-фармакологическая функция“" [4].

\section{Методика исследований}

Синтез исследуемых замещенных бензоксазола осуществлен в Белорусском госуниверситете авторами работы, а их экспериментальные спектры поглощения и флуоресценции получены в Институте физики НАН Беларуси также авторами настоящей работы. Спектры поглощения исследованных соединений регистрировались на спектрофотометре Cary-500 Scan UV-Vis-NIR (Varian, CША) в гексане и этаноле при концентрации $10^{-4} \mathrm{~mol} / \mathrm{l}$. Измерения скорректированных спектров флуоресценции и спектров возбуждения флуоресценции проводились на модернизированном спектрофлуориметрическом комплексе СДЛ-2 (ЛОМО, СССР), основанном на монохроматорах возбуждения и регистрации - МДР-12 и МДР-23 соответственно. Управление комплексом с помощью персонального компьютера описано в [5]. В качестве источника возбуждения использовалась ксеноновая лампа ДКсШ-120. Регистрация светового сигнала после прохождения монохроматора осуществлялось фотоумножителем ФЭУ-100 (диапазон 230-800 нм) в режиме счета фотонов. Квантовые выходы флуоресценции растворов в этаноле оценивались относительным методом. В качестве эталона использовался раствор хинина в 0.1нормальной серной кислоте (квантовый выход $\gamma=0.55$ ).

Теоретические исследования зависимости спектрально-люминесцентных свойств многоатомных молекул от их химической и электронной структур являются важнейшей задачей теории электронного строения молекулярных систем. Решение названной задачи в большинстве случаев не может быть получено на чисто экспериментальной (эмпирической) основе. Физикохимические (в том числе спектрально-люминесцентные) характеристики молекул являются отражением свойств их электронных оболочек, которые определяются химическим строением соединений. Зависимость же электронной структуры молекулы от ее строения может быть корректно изучена только с привлечением квантовохимических методов.
Кратко напомним, как связаны вычисленные теоретические величины с экспериментально измеряемыми характеристиками спектров поглощение (излучения, флуоресценции). Основной из них является оптическая плотность $D(v)=\varepsilon(v) C l$, где $\varepsilon(v)$ - молярный десятичный коэффициент экстинкции $(1 / \mathrm{mol} \cdot \mathrm{cm}), C-$ концентрация молекул (в $\mathrm{mol} / \mathrm{l}), l$ - толщина слоя $($ в $\mathrm{cm})$, $v$ - волновое число (частота, энергия, в $\mathrm{cm}^{-1}$ ). Для характеристики интенсивности полос электронных спектров обычно используется безразмерная величина $f$, называемая силой осциллятора, которая рассчитывается с помощью нестрогой формулы

$$
f=4.32 \cdot 10^{-9} \int \varepsilon(v) d v .
$$

Излучательный (поглощение или излучение) или безызлучательный электронные переходы (внутренняя или интеркомбинационная конверсия) происходят между электронно-колебательными (вибронными) состояниями молекулы. В теоретическом плане это обеспечивает выполнение закона сохранения энергии в ходе осуществления электронного перехода. В то же время, согласно принципу Франка-Кондона, в ходе осуществления электронного перехода сохраняются геометрические характеристики исходного вибронного состояния (термодинамически равновесного колебательного распределения). Это означает, что вычисленные в квантово-химическом расчете энергии электронных переходов соответствуют максимумам соответствующих полос поглощения (излучения). Обычно электронная полоса поглощения может быть аппроксимирована гауссовой кривой с определенной полушироной $\Delta v$. Если предположить $\Delta v \approx 5000 \mathrm{~cm}^{-1}$, то получим приближенное соотношение $f \approx 10^{-5} \varepsilon\left(v_{\max }\right)$, которое полезно при сравнении теоретических $(f)$ и экспериментальных характеристик спектров $\left(\varepsilon\left(v_{\max }\right)\right)$.

В настоящем исследовании квантово-химические расчеты выполнены полуэмпирическим методом частичного пренебрежения дифференциальным перекрыванием (ЧПДП) с использованием комплекса программ и оригинальной параметризации [6], созданных в отделе фотоники молекул Сибирского физико-технического института при Томском государственном университете специально для исследования проблем фотоники многоатомных органических соединений.

Использованный вариант метода ЧПДП позволяет рассчитывать энергии и силы осцилляторов электронных переходов, распределение электронной плотности на атомах и молекулярных фрагментах и ее изменение при электронном возбуждении в сравнении с основным состоянием. Величины констант скоростей радиационного распада $\left(k_{r}\right)$, безызлучательнных переходов (внутренней, $\left.k_{i c}\right)$ и интеркомбинационной $\left(k_{S T}\right)$ конверсии рассчитывались по методологии, описанной в [7], носят оценочный характер и позволяют установить тенденции изменения квантового выхода флуоресценции 
<smiles>COc1cc(C=O)ccc1O</smiles><smiles>COc1c(C)c(C)c(C)c(O)c1C(=O)O</smiles>

$a 1$<smiles>COc1cc(C=O)cc(OC)c1O</smiles><smiles></smiles>

$a 2$<smiles>COc1ccccc1C=O</smiles>

$c$<smiles>COc1c(C)c(C(C)[OH+][OH+])c(C)c(C)c1O</smiles>

$a 3$

Рис. 1. Структурные формулы исследованных замещенных бензальдегидов: $a-$ ванилин, $b-$ сиреневый альдегид, $c-o$ анисовый альдегид. В качестве примера приведены структуры протолитических форм ванилина: $a 1-\mathrm{H} \Phi(q=0), a 2-\mathrm{A} \Phi$ $(q=-1 e)$ и $a 3-\mathrm{K} \Phi(q=1 e)$.

$\left(\gamma=k_{r} / k_{r}+k_{i c}+k_{S T}\right)$ в рядах сходно построенных соединений [8].

Геометрия основного состояния изученных соединений оптимизировалась методом АМ1 [9]. При расчете заряженных форм приняты следующие модели молекул. В АФ изменения геометрии ограничены изменениями длин химических связей, чтобы не нарушать валентность атомов молекулы. Катионы (протонированные формы) моделировались как комплексы с водородной связью между молекулами замещенных бензальдегидов и протоном, сольватированным молекулой метилового спирта (рис. 1). При моделировании КФ для обоснованного построения комплекса использован метод молекулярного электростатического потенциала (МЭСП) $[10,11]$, позволяющий определить не только наиболее электроноакцепторный центр в молекуле, но и место присоединения протона.

Для корректного расчета спектра излучения определялась геометрия возбужденного состояния исходя из изменения электронной плотности на химических связях $P_{A B}$ исследуемых молекул (по Малликену [12]) при возбуждении относительно основного состояния. При этом использована известная линейная зависимость между длиной химической связи и ее заселенностью. Тогда изменение длины связи при переходе в возбужденное состояние можно описать следующим образом:

$$
\Delta R_{A B}^{*}=-k \Delta P_{A B}^{*},
$$

где $\Delta P_{A B}^{*}$ - изменение заселённости связи при переходе молекулы из основного состояния в возбуждённое.
Значение коэффициента $k=0.46$ было получено из изменения длины $\mathrm{C}-\mathrm{C}$-связей бензола при $S_{0} \rightarrow S_{1}$ переходе [13].

Следует отметить, что спектрально-люминесцентные свойства заряженных форм замещенных бензальдегидов изучены недостаточно. Наиболее полными можно считать экспериментальные данные по спектрам поглощения и флуоресценции ванилина автора [14] и спектры поглощения АФ ванилина и сиреневого альдегида в монографии [15].

\section{Результаты и обсуждение}

Подробное экспериментальное исследование заряженных форм ванилина, проведенное в [14], показало, что водный раствор ванилина проявляет большую зависимость спектров поглощения и флуоресценции от $\mathrm{pH}$ раствора. В зависимости от величины $\mathrm{pH}$ раствора ванилин может существовать в трех протолитических формах: НФ, АФ и КФ (рис. 1). АФ ванилина образуется в основном состоянии в результате отрыва протона от гидроксильной группы $(\mathrm{pH}>7.2)$ как самой слабой, о чем свидетельствует заселенность $\left(P_{A B}\right)$ связи $\mathrm{O}-\mathrm{H}$ в исследуемых соединениях по сравнению с другими $\mathrm{C}-\mathrm{H}$-связями в них: $P_{\mathrm{O}-\mathrm{H}}=0.572 e, P_{\mathrm{C}_{-} \mathrm{CH}_{3}}=0.766 e$, $P_{\text {Cap }-\mathrm{H}}=0.890 e, P_{\mathrm{C}-\mathrm{H}(\mathrm{COH})}=0.773 e[3]$.

КФ образуется в результате протонирования $(\mathrm{pH}<-1)$ атома кислорода альдегидной группы, обладающего самыми высокими акцепторными 

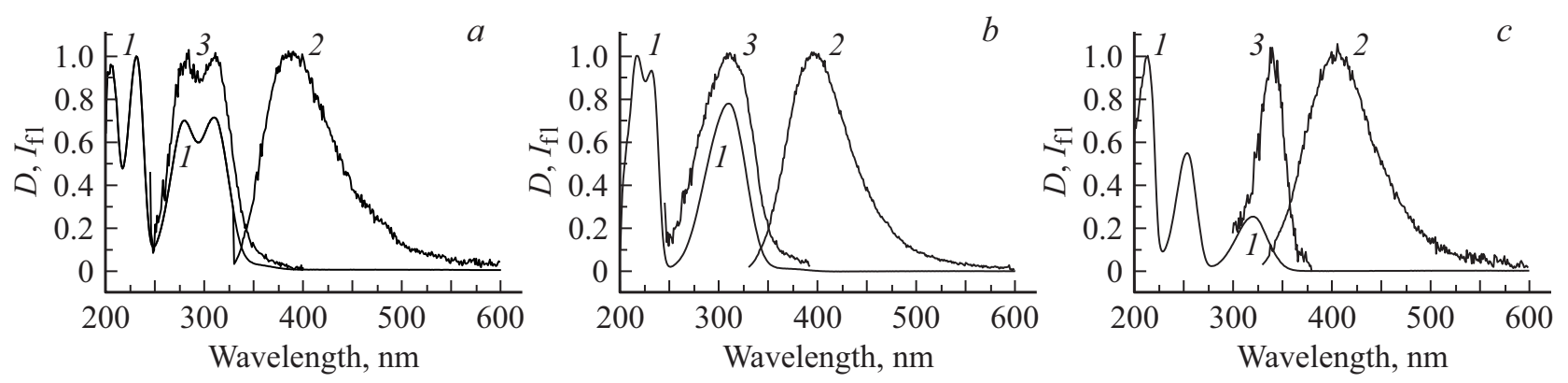

Рис. 2. Спектры поглощения $D(1)$, флуоресценции (2), возбуждения флуоресценции (3) в этаноле: ванилин (a), сиреневый альдегид $(b), o$-анисовый альдегид $(c)$. Длина волны возбуждающего света $-330 \mathrm{~nm}$, длина волны регистрации - $410 \mathrm{~nm}$. Спектры 2 и 3 приведены в относительных единицах.

свойствами в сравнении с другими атомами кислорода молекул. Поскольку этанол как растворитель по своим протоноакцепторным свойствам близок к воде и, кроме этого, зачастую содержит некоторое количество воды, можно предположить присутствие КФ в этанольных растворах исследуемых замещенных бензальдегидов как в поглощении, так и во флуоресценции. Так, из эксперимента [14] следует, что в водных растворах ванилина в спектре поглощения одновременно наблюдаются НФ и АФ ванилина. Авторы [16], исследуя влияние состава растворителя вода-спирт на окисление ванилина на платиновом электроде методом постоянно-токовой вольт-амперометрии пришли к выводу, что в щелочной среде электрохимическому окислению либо предшествует депротонизация, либо процессы депротонизации и окисления протекают одновременно. Этот вывод служит косвенным подтверждением присутствия в спектре поглощения раствора кроме НФ, также АФ ванилина.

Образование заряженных форм АФ и КФ следует ожидать и в спиртовом растворе сиреневого альдегида, тогда как в $о$-анисовом альдегиде возможно образование только двух форм (НФ и КФ) по причине отсутствия гидроксильной группы.

На рис. 2 приведены экспериментальные спектры поглощения и флуоресценции исследованных соединений в этаноле.

\section{Спектры поглощения заряженных форм}

В табл. 1 приведены результаты расчета характеристик спектров поглощения заряженных форм ванилина, $o$-анисового и сиреневого альдегидов в сравнении с НФ и экспериментальными спектрами поглощения АФ. Спектры АФ ванилина и сиреневого альдегида получены в подщелоченном растворе этанола [15]. Из расчетов следует, что отрыв протона от гидроксильной группы в АФ приводит к сильному понижению энергии $\pi \pi^{*}$ переходов и повышению энергии состояний $n \pi^{*}$-типа.

Анализ рассчитанных характеристик спектров поглощения НФ и АФ ванилина показал, что в области 240-420 nm заряженная форма имеет на одну полосу меньше по сравнению с НФ, а весь спектр ее сдвинут в область длинных волн по сравнению со спектром НФ. Анализ молекулярных орбиталей (МО) в конфигурации, образующей длинноволновую полосу поглощения в анионе ванилина, показал, что эта полоса образованна одним $S_{0} \rightarrow S_{1}\left(\pi \pi^{*}\right)$-переходом и аналогична $S_{0} \rightarrow S_{2}\left(\pi \pi^{*}\right)$-переходу НФ, меньшей энергии, но большей интенсивности. Между двумя полосами в экспериментальном спектре поглощения АФ ванилина [15] расположено плато с небольшим перегибом на $395 \mathrm{~nm}$, который по своей орбитальной природе соответствует $S_{0} \rightarrow S_{3}\left(\pi \pi^{*}\right)$-переходу НФ ванилина.

Согласно результатам расчетов, длинноволновая полоса в спектре поглощения АФ сиреневого альдегида образована двумя электронными переходами, первый из которых соответствует $S_{0} \rightarrow S_{3}\left(\pi \pi^{*}\right)$-, а второй $S_{0} \rightarrow S_{5}\left(\pi \pi^{*}\right)$-переходу НФ молекулы. Сравнение рассчитанных и экспериментальных полос поглощения АФ ванилина и сиреневого альдегида обнаруживает удовлетворительное соответствие эксперименту, что позволяет предполагать и удовлетворительное соответствие эксперименту для КФ исследованных соединений.

Длинноволновая полоса в спектре поглощения КФ $o$-анисового альдегида образована двумя электронными переходами $S_{0} \rightarrow S_{1}\left(\pi \pi^{*}\right)$ и $S_{0} \rightarrow S_{2} \quad\left(n \pi^{*}\right)$. По локализации МО, образующих $S_{1}\left(\pi \pi^{*}\right)$-состояние КФ $о$-анисового альдегида, можно утверждать, что оно соответствует $S_{2}\left(\pi \pi^{*}\right)$-состоянию НФ молекулы. В КФ ванилина длинноволновая полоса поглощения образована электронными $S_{0} \rightarrow S_{1}\left(\pi \pi^{*}\right)$, $S_{0} \rightarrow S_{2}\left(n \pi^{*}\right)$ - и $S_{0} \rightarrow S_{3}\left(\pi \pi^{*}\right)$-переходами, из которых состояние $S_{1}\left(\pi \pi^{*}\right)$ КФ соответствует $S_{2}\left(\pi \pi^{*}\right)$ НФ, а $S_{3}\left(\pi \pi^{*}\right)-S_{4}\left(\pi \pi^{*}\right)$ НФ (табл. 1). В спектре катиона сиреневого альдегида ситуация аналогична ванилину.

Отметим, что в спектрах поглощения заряженных форм исследуемых замещенных бензальдегидов в области 220-420 nm не возникает новых полос поглощения с локализацией МО, отличной от НФ. В случае АФ ванилина и сиреневого бензальдегида имеет место хорошее соответствие расчета и эксперимента (табл. 1).

Отрыв протона от гидроксильной группы заряжает молекулы замещенных бензальдегида отрицательно, однако большая часть отрицательного заряда локализуется на 
Таблица 1. Экспериментальные и теоретические характеристики спектров поглощения протолитических форм замещенных бензальдегидов

\begin{tabular}{|c|c|c|c|c|c|c|c|c|c|}
\hline \multicolumn{9}{|c|}{ Расчет } & \multirow{2}{*}{$\begin{array}{c}\text { Эксперимент } \\
\text { АФ }[15]\end{array}$} \\
\hline & $\mathrm{H} \Phi$ & & & КФ & & & $\mathrm{A} \Phi$ & & \\
\hline Состояние & $E_{i}, \mathrm{~cm}^{-1}$ & $f$ & Состояние & $E_{i}, \mathrm{~cm}^{-1}$ & $f$ & Состояние & $E_{i}, \mathrm{~cm}^{-1}$ & $f$ & $\lambda_{\max }, \mathrm{nm}\left(E_{\max }, \mathrm{cm}^{-1}\right)$ \\
\hline
\end{tabular}

$o$-Анисовый альдегид

\begin{tabular}{|c|c|c|c|c|c|c|c|c|c|}
\hline$S_{1}(n \pi)$ & 25240 & 0.0 & $S_{1}(\pi \pi)$ & 26330 & 0.138 & & & & \\
\hline$S_{2}(\pi \pi)$ & 32170 & 0.215 & $S_{2}(n \pi)$ & 30810 & 0.0 & & & & \\
\hline$S_{3}(\pi \pi)$ & 36040 & 0.142 & $S_{3}(\pi \pi)$ & 34060 & 0.208 & \multicolumn{3}{|c|}{ Нет АФ } & \\
\hline$S_{5}(\pi \pi)$ & 42330 & 0.590 & $S_{6}(\pi \pi)$ & 42120 & 0.476 & & & & \\
\hline$S_{7}(\pi \pi)$ & 45630 & 0.162 & $S_{11}(\pi \pi)$ & 49550 & 0.538 & & & & \\
\hline$S_{12}(\pi \pi)$ & 49450 & 0.286 & $S_{12}(\pi \pi)$ & 50310 & 0.210 & & & & \\
\hline \multicolumn{10}{|c|}{ Ванилин } \\
\hline$S_{1}(n \pi)$ & 27490 & 0.0 & $S_{1}(\pi \pi)$ & 27880 & 0.229 & $S_{1}(\pi \pi)$ & 28830 & 0.586 & \multirow{2}{*}{$355(28170)$} \\
\hline$S_{2}(\pi \pi)$ & 32820 & 0.120 & $S_{2}(n \pi)$ & 31460 & 0.0 & $S_{2}(n \pi)$ & 29380 & 0.0 & \\
\hline$S_{3}(\pi \pi)$ & 34940 & 0.162 & $S_{3}(\pi \pi)$ & 31650 & 0.251 & $S_{3}(\pi \pi)$ & 31440 & 0.156 & 300 (33300) (пер.) \\
\hline$S_{5}(\pi \pi)$ & 41560 & 0.647 & $S_{5}(\pi \pi)$ & 39108 & 0.360 & $S_{6}(\pi \pi)$ & 37630 & 0.028 & \multirow{2}{*}{$255(39220)$} \\
\hline$S_{7}(\pi \pi)$ & 44190 & 0.316 & $S_{6}(\pi \pi)$ & 41840 & 0.069 & $S_{9}(\pi \pi)$ & 41950 & 0.157 & \\
\hline$S_{11}(\pi \pi)$ & 47520 & 0.205 & $S_{10}(\pi \pi)$ & 47108 & 0.421 & $S_{13}(\pi \pi)$ & 46660 & 0.374 & \\
\hline
\end{tabular}

Сиреневый альдегид

\begin{tabular}{c|c|c|c|c|c|c|c|c|c|}
\hline$S_{1}(n \pi)$ & 27810 & 0.0 & $S_{1}(\pi \pi)$ & 24480 & 0.032 & $S_{1}(\pi \pi)$ & 26500 & 0.513 & \multirow{2}{*}{$370(27030)$} \\
\hline$S_{2}(\pi \pi)$ & 30290 & 0.032 & $S_{2}(\pi \pi)$ & 27290 & 0.491 & $S_{2}(\pi \pi)$ & 29020 & 0.131 & \\
\hline$S_{3}(\pi \pi)$ & 32050 & 0.278 & $S_{3}(n \pi)$ & 33030 & 0.0 & $S_{3}(n \pi)$ & 29390 & 0.0 & \\
\hline$S_{5}(\pi \pi)$ & 32500 & 0.407 & $S_{5}(\pi \pi)$ & 37790 & 0.101 & $S_{9}(\pi \pi)$ & 38840 & 0.150 & $255(39220)$ \\
\hline$S_{8}(\pi \pi)$ & 40650 & 0.530 & $S_{7}(\pi \pi)$ & 40980 & 0.191 & $S_{13}(\pi \pi)$ & 44480 & 0.353 & \\
\hline$S_{12}(\pi \pi)$ & 45730 & 0.110 & $S_{10}(\pi \pi)$ & 44150 & 0.190 & $S_{15}(\pi \pi)$ & 47220 & 0.090 & \\
\hline$S_{13}(\pi \pi)$ & 46620 & 0.278 & $S_{12}(\pi \pi)$ & 44660 & 0.620 & & & &
\end{tabular}

Примечание. $E_{i}$ - энергия чисто электронного перехода, $f-$ сила осциллятора этого перехода.

атоме кислорода, оставшегося после отрыва протона от гидроксильной группы (табл. 2).

Остальная часть отрицательного заряда усиливает акцепторные свойства бензольного кольца, альдегидной и метокси-групп в состояниях $\pi \pi^{*}$-типа анионов анилина и сиреневого альдегида.

В КФ исследованных соединений бензольный цикл проявляет более сильные, чем АФ, акцепторные свойства, особенно в $n \pi^{*}$-состоянии (табл. 3 ).

Ситуация в группе $\mathrm{COHH}^{+}$КФ исследованных молекул более сложная: акцепторные или донорные свойства этой группы в возбужденных состояниях меняются по сравнению с НФ. Так, например, в $S_{0}$-состоянии НФ группа $\mathrm{COH}$ во всех соединениях проявляет акцептор- ные свойства, тогда как группа $\mathrm{COHH}^{+}$становится донором. Или, например, в $S_{2}\left(\pi \pi^{*}\right)$-состоянии НФ группа $\mathrm{COH} \mathrm{является} \mathrm{акцептором,} \mathrm{а} \mathrm{в} S_{1}\left(\pi \pi^{*}\right)$-состоянии КФ резко снижает свои акцепторные свойства.

\section{Флуоресценция заряжсенных борм}

Экспериментальные и рассчитанные характеристики флуоресценции исследованных молекул приведены в табл. 4. Согласно этим данным, все замещенные бензальдегиды, исследованные в настоящей работе, слабо флуоресцируют с $\lambda_{\mathrm{fl}}=410 \mathrm{~nm}$ и квантовыми выходами $0.022,0.012$ и 0.008 (o-анисовый альдегид, ванилин, сиреневый альдегид). Главное важное отличие спектров поглощения и флуоресценции заряженных форм 
Таблица 2. Распределение электронной плотности в АФ замещенных бензальдегидов при возбуждении

\begin{tabular}{c|c|c|c|c}
\hline \multirow{2}{*}{ Состояние } & \multicolumn{4}{|c}{ Электронная плотность на фрагментах молекул, $e$} \\
\cline { 2 - 5 } & Бензольное кольцо & Группа СОН & Оон & Группы ОСН $(1), \mathrm{OCH}_{3}(2)$ \\
\hline \multicolumn{5}{|c|}{ Анион ванилина } \\
\hline$S_{0}$ & +0.128 & -0.225 & -0.746 & -0.157 \\
\hline$S_{1}(\pi \pi)$ & +0.372 & -0.659 & -0.618 & -0.095 \\
\hline$S_{2}(n \pi)$ & -0.124 & +0.047 & -0.784 & -0.140 \\
\hline$S_{6}(\pi \pi)$ & +0.086 & -0.273 & -0.587 & -0.023 \\
\hline \multicolumn{5}{|c|}{ Анион сиреневого альдегида } \\
\hline$S_{0}$ & & -0.232 & -0.746 & $-0.152,-0.147$ \\
\hline$S_{1}(\pi \pi)$ & +0.277 & -0.658 & -0.630 & $-0.112,-0.111$ \\
\hline$S_{3}(\pi \pi)$ & +0.511 & -0.240 & -0.595 & $-0.116,-0.111$ \\
\hline
\end{tabular}

Таблица 3. Распределение электронной плотности в КФ замещенных бензальдегидов при возбуждении

\begin{tabular}{|c|c|c|c|c|}
\hline \multirow{2}{*}{ Состояние } & \multicolumn{4}{|c|}{ Электронная плотность на фрагментах молекул, $e$} \\
\hline & Бензольное кольцо & Группа $\mathrm{COHH}^{+}$ & Группа ОН & Группы $\mathrm{OCH}_{3}(1), \mathrm{OCH}_{3}(2)$ \\
\hline \multicolumn{5}{|c|}{ Катион o-анисовый альдегида } \\
\hline$S_{0}$ & +0.490 & +0.542 & - & -0.032 \\
\hline$S_{1}(\pi \pi)$ & +0.874 & -0.022 & - & +0.148 \\
\hline$S_{2}(n \pi)$ & +0.907 & +0.106 & - & -0.013 \\
\hline$S_{3}(\pi \pi)$ & +0.662 & +0.201 & - & +0.138 \\
\hline \multicolumn{5}{|c|}{ Катион ванилина } \\
\hline$S_{0}$ & +0.580 & +0.528 & -0.051 & -0.057 \\
\hline$S_{1}(\pi \pi)$ & +0.881 & -0.037 & +0.014 & +0.142 \\
\hline$S_{2}(n \pi)$ & +0.960 & -0.002 & +0.015 & +0.027 \\
\hline$S_{3}(\pi \pi)$ & +0.452 & +0.319 & +0.038 & +0.191 \\
\hline \multicolumn{5}{|c|}{ Катион сиреневого альдегида } \\
\hline$S_{0}$ & +0.557 & +0.618 & -0.067 & $-0.049,-0.059$ \\
\hline$S_{1}(\pi \pi)$ & +0.882 & +0.001 & -0.074 & $+0.078,+0.113$ \\
\hline$S_{2}(\pi \pi)$ & +0.492 & +0.077 & +0.065 & $+0.119,+0.247$ \\
\hline$S_{3}(n \pi)$ & +0.525 & +0.271 & +0.043 & $+0.052,+0.109$ \\
\hline
\end{tabular}

от НФ - орбитальная природа $S_{1}$-состояния. В НФ $S_{1}$-состояние имеет орбитальную природу $n \pi^{*}$-типа [3], что объясняет отсутствие флуоресценции. В заряженных формах $S_{1}$-состояние имеет орбитальную природу $\pi \pi^{*}$-типа (т.е. происходит инверсия $n \pi^{*}$ и $\pi \pi^{*}$ состояний), что и обусловливает наличие флуоресценции.

Экспериментальные данные спектров в этаноле формально дают величину стоксова сдвига флуоресценции незаряженных замещенных бензальдегидов в пределах $6900-7900 \mathrm{~cm}^{-1}$. Однако указанная величина стоксова сдвига определена без учета наличия $S_{1}(n \pi)$-состояния, не проявляющегося в спектре поглощения. Учитывая, что рассчитанная энергия состояния $S_{1}\left(n \pi^{*}\right)$ находится в пределах 26000-27000 $\mathrm{cm}^{-1}$, стоксов сдвиг в исследуемых незаряженных формах не превышает $2500 \mathrm{~cm}^{-1}$, что свидетельствует о незначительных перестройках структуры поглощающих молекул после возбуждения. 
Таблица 4. Характеристики флуоресценции (максимум полосы $\lambda_{\mathrm{fl}}$ и квантовый выход $\gamma$ ) протолитических форм замещенных бензальдегидов

\begin{tabular}{|c|c|c|c|c|c|c|c|c|}
\hline \multicolumn{7}{|c|}{ Расчет } & \multirow{2}{*}{\multicolumn{2}{|c|}{$\frac{\text { Эксперимент }}{\text { (этанол) }}$}} \\
\hline \multirow{2}{*}{ Соединение } & \multirow{2}{*}{$\begin{array}{c}\text { Протолитическая } \\
\text { форма }\end{array}$} & \multirow{2}{*}{$\lambda_{\mathrm{fl}}, \mathrm{nm}\left(\mathrm{cm}^{-1}\right)$} & \multirow{2}{*}{$k_{r}, \mathrm{~s}^{-1}$} & \multirow{2}{*}{$k\left(S_{1}-S_{0}\right), \mathrm{s}^{-1}$} & \multirow{2}{*}{$k\left(S_{1}-T_{i}\right), \mathrm{s}^{-1}$} & \multirow{2}{*}{$\gamma$} & & \\
\hline & & & & & & & $\lambda, \mathrm{nm}\left(E_{\mathrm{fl}}, \mathrm{cm}^{-1}\right)$ & $\Gamma$ \\
\hline \multirow{2}{*}{$o$-анисовый альдегид } & Нейтральная & $386(25670)$ & $3 \cdot 10^{4}$ & $10^{-7}$ & $4 \cdot 10^{11}$ & $>10^{-4}$ & \multirow{2}{*}{$410(24390)$} & \multirow{2}{*}{0.022} \\
\hline & Катионная & $381(26220)$ & $9 \cdot 10^{7}$ & $2 \cdot 10^{5}$ & $2 \cdot 10^{9}$ & 0.035 & & \\
\hline \multirow{3}{*}{ Ванилин } & Нейтральная & $376(26600)$ & $2 \cdot 10^{2}$ & $10^{-7}$ & $8 \cdot 10^{10}$ & $>10^{-4}$ & \multirow{3}{*}{$410(24390)$} & \multirow{3}{*}{0.012} \\
\hline & Анионная & $372(26860)$ & $3 \cdot 10^{8}$ & $1 \cdot 10^{5}$ & $6 \cdot 10^{11}$ & $5 \cdot 10^{-4}$ & & \\
\hline & Катионная & $419(23870)$ & $8 \cdot 10^{7}$ & $2 \cdot 10^{6}$ & $2 \cdot 10^{9}$ & 0.038 & & \\
\hline \multirow{3}{*}{ Сиренвый альдегид } & Нейтральная & $378(26600)$ & $2 \cdot 10^{2}$ & $10^{-7}$ & $2 \cdot 10^{10}$ & $>10^{-4}$ & \multirow{3}{*}{$410(24390)$} & \multirow{3}{*}{0.008} \\
\hline & Анионная & $387(25840)$ & $2 \cdot 10^{8}$ & $10^{-7}$ & $6 \cdot 10^{11}$ & $4 \cdot 10^{-4}$ & & \\
\hline & Катионная & $420(23810)$ & $8.3 \cdot 10^{7}$ & $1 \cdot 10^{6}$ & $2.5 \cdot 10^{9}$ & 0.032 & & \\
\hline
\end{tabular}

Совпадение положения максимумов спектров поглощения и возбуждения флуоресценции ванилина и сиреневого альдегида позволяет утверждать, что наблюдаемая полоса флуоресценции этих соединений принадлежит одному типу частиц каждой из молекул. Значительное несовпадение спектров поглощения и возбуждения флуоресценции ( $1800 \mathrm{~cm}^{-1}$ в длинноволновой полосе) регистрируется для $o$-анисового альдегида. Это несовпадение можно объяснить наличием в растворе двух конформеров с близкими характеристиками флуоресценции $\left(\lambda_{\mathrm{fl}}, \gamma\right)$. Оптимизированная геометрия этой молекулы дает конформер, приведенный на рис. 1. По нашему мнению, возможна и другая конфигурация молекулы, в которой группа $\mathrm{COH}$ развернута относительно связи $\mathrm{C}-\mathrm{COH}$ на $180^{\circ}$. Расчеты показали, что конформеры $o$-анисового альдегида имеют различающиеся спектры поглощения, что и приводит к несовпадению максимумов длинноволновых полос спектров поглощения и возбуждения флуоресценции. Рассчитанные максимумы полос флуоресценции конформеров близки по положению $-\lambda_{\mathrm{fl} 1}=389 \mathrm{~nm}, \lambda_{\mathrm{fl} 2}=382 \mathrm{~nm}$, разница энергий между ними меньше $500 \mathrm{~cm}^{-1}$.

Сравнение результатов расчета с экспериментом для спектров флуоресценции проводилось по двум характеристикам: положению полосы флуоресценции и квантовому выходу флуоресценции. Наиболее близка рассчитанная энергия флуоресценции экспериментальному максимуму полосы флуоресценции для КФ ванилина и сиреневого альдегида. Для $o$-анисового альдегида это соответствие хуже. Рассчитанный квантовый выход флуоресценции КФ выше, чем АФ, что позволяет предполагать, что флуоресценция на $410 \mathrm{~nm}$, наблюдаемая экспериментально в этанольных растворах замещенных бензальдегидов, принадлежит КФ рассмотренных соединений.
В целом анализ экспериментальных и расчетных данных (табл. 4) позволяет сделать вывод, что флуоресценция ванилина, $о$-анисового и сиреневого альдегидов, наблюдаемая на длине волны $410 \mathrm{~nm}$, принадлежит КФ данных соединений. Отметим, что в ванилине и сиреневом альдегиде также имеется возможность очень слабой флуоресценции АФ.

\section{Заключение}

1. На основании полученных результатов можно утверждать, что спектр поглощения заряженных форм в области от 240-420 nm образован электронными переходами такой же локализации и такой же орбитальной природы, что и спектры поглощения НФ. Различие состоит лишь в сдвиге спектра поглощения заряженных форм в область меньшей энергии и изменении интенсивности.

2. В заряженных формах исследованных соединений по отношению к НФ имеет место инверсия $n \pi^{*}$ - и $\pi \pi^{*}$-состояний. При этом за флуоресценцию в этаноле 2-метоксибензальдегида (o-анисовый альдегид), 3-метокси-4-гидроксибензальдегида (ванилин), 3,5диметокси-4-гидроксибензальдегида (сиреневый альдегид) ответственны КФ этих форм этих соединений.

\section{Финансирование работы}

Результаты были получены в рамках выполнения государственного задания Министерства образования и науки России, проект № 4.6027.2017/8.9 и задания 1.4.02 ГПНИ „Фотоника и оптомикроэлектроника“ Беларуси.

\section{Конфликт интересов}

Авторы заявляют, что у них нет конфликта интересов. 


\section{Список литературы}

[1] Weller F. // Naturwissenschaft. 1955. V.B. 42. S. 175.

[2] Mohapatra M., Mishra A.K. // Photochem. Photobiol. Sci. 2019. V. 18. P. 2830. doi 10.1039 /c9pp00294d

[3] Базыль О.К., Артюхов В.Я., Майер Г.В., Першукевич П.П., Бельков М.В., Шадыро О.И., Самович С.Н. // Опт. и спектр. 2019. Т. 127. В. 2. С. 242; Bazyl' O.K., Artyuhov V.Ya., Mayer G.V., Pershukevich P.P., Bel'kov M.V., Shadyro O.I., Samovich S.N. // Opt. Spectrosc. 2019. V. 127. N 2. P. 242. doi $10.1134 / \mathrm{S} 00304006 \mathrm{X}$

[4] Tolstorozhev G.B., Mayer G.V., Belkov M.V., Shadyro O.I. // Rus. Phys. J. 2016. V. 59. N 4. P. 544. doi 10.1007/s11182016-0804-x

[5] Воропай Е.С., Самцов М.П., Радько М.Е., Каплевский К.Н., Першукевич П.П., Бельков М.В., Ермаличкий Ф.A. // Лазерная и оптико-электронная техника: сб. науч. ст. / Под ред. Манак И.С. Минск: Акад. упр. при Президенте РБ, 2006. В. 10. С. 200.

[6] Артюхов В.Я., Галеева А.И. // Изв. вузов. Физика. 1986. № 11. C. 96; Artyukhov V.Ya., Galeeva A.I. // Rus. Phys. J. 1986. N 11. P. 949.

[7] Майер Г.В., Плотников В.Я., Артюхов В.Я. // Изв. вузов. Физика. 2016. T. 59. № 4. C. 42; Mayer G.V., Plotnikov V.G., Artyukhov V.Ya. // Rus. Phys. J. 2016. V. 59. N 4. P. 513. doi 10.1007/s 11182-016-0801-07

[8] Артюхов В.Я., Копылова Т.Н., Самсонова Л.Г., Селиванов Н.И., Плотников В.Г., Сажников В.А., Хлебунов А.А., Майер Г.В., Албимов М.В. // Изв. вузов. Физика. 2008. № 10. C. 94-107; Artyukhov V.Ya, Kopylova T.N., Samsonova L.G., Selivanov N.I., Plotnikov V.G., Saznikov V.A., Khlebunov A.A., Mayer G.V., Alfimov M.D. // Rus. Phys. J. 2008. N 10. P. 1096.

[9] http://www.cambridgesoft.com.

[10] Scrocco E., Tomasi J. // Advances in Quantum Chemistry. 1978. V. 11. P. 115.

[11] Артюхов В.Я. // Журн. структурн. химии. 1978. Т. 19. № 3. C. 418; Artyukhov V.Ya. // J. Struct. Chem. 1978. V. 19. N 3. P. 364.

[12] Mulliken R.S. // J. Chem. Phys. 1955. V. 23. N 10. P. 1833.

[13] Герцберг Г. Электронная структура и строение многоатомных соединений. М.: Мир, 1969. 772 с.; Herzberg G. Molecular Spectra and Molecular Structure. Toronto-New York-London, 1969. 772 p.

[14] Вусович О.В. Автореф. канд.дисс. Томск, 2016. 134 с. Режим доступа: http://ams.tsu.ru/TSU/QualificationDep/cosearchers.nsf/72A8038F9DD1EB9C472580B300309353/ \$file/\%D0\%92\%D1\%83\%D1\%81\%D0\%BE\%D0\%B2\%D0\% B8\%D1\%87_\%D0\%9E.\%D0\%92._\%D0\% 94\%D0\%B8\%D1\%81\%D1\%81\%D0\%B5\%D1 \%80\%D1\%82\%D0\%B0\%D1\%86\%D0\%B8\%D1\%8F.pdf.

[15] Скурихин И.М. Химия коньяка и бренди. М.: ДеЛи Принт, 2005. 296 c.; Skourikhin J.M. The Mistry of Cognac and Brendy. M.: DeLi Print, 2005. 296 p.

[16] Боголицын К.Г., Иванченко Н.Л., Потапова Е.Ф., Шкаев А.Н. // Химия растительного сырья. 2006. № 1. С. 11. 